\title{
Improving the specificity of an anti-estradiol antibody by random mutagenesis and phage display
}

\author{
S. Coulon $^{\mathrm{a}, *}$, E. Mappus $^{\mathrm{b}}$, C.Y. Cuilleron ${ }^{\mathrm{b}}$ and \\ D. Baty ${ }^{\mathrm{a}}$ \\ ${ }^{\mathrm{a}}$ CNRS UPR 9027, Laboratoire d'Ingénierie des \\ Systèmes Macromoléculaires, 31 chemin Joseph \\ Aiguier, 13402 Marseille Cedex 20, France \\ b INSERM U329, Hopital Debrousse, 29 rue soeur \\ Bouvier, 69322 Lyon Cedex, France
}

Estradiol is a steroid hormone secreted by endocrine glands (ovary, testis) [3]. The variation of estradiol levels in blood or urine may be associated with many pathologies such as hormone-dependent cancers and diseases of sexual behaviour [5]. Measurements of the concentration of estradiol in blood or urine is of great importance both for clinical diagnosis and during therapy. Competitive immunoassays using an antisteroid antibody and a steroid tracer have become the main routine method to measure steroid concentrations. Obviously, the antibody must be very specific to be able to discriminate between estradiol and other steroid analogues. At present, none of the available antibodies are able to provide unambiguous measurements of very low concentrations of estradiol directly in blood or urine [2]. First, the molecular structures of steroids are very similar, and consequently, the isolation of a specific steroid antibody devoid of cross-reactions with analogues is difficult. Second, the steroids are small molecules unable to cause an immunogenic reaction. They need to be coupled to an immunogenic protein like bovine serum albumin. Consequently, the antibody has often a weaker affinity for the free steroid than for the immunogen [8] and exhibits a lower specificity for the site of coupling.

*Correspondence to: Tel.: +334911645 61; Fax: +3349171 21 24; E-mail: coulon@ibsm.cnrs-mrs.fr.
The monoclonal anti-estradiol antibody (D) has been prepared from mice immunized with an estradiol-7carboxymethyloximino-BSA conjugate. The heavy and light chains of the antibody have been cloned into a phagemid vector ( $\mathrm{pHENI}$ ) in $\mathrm{scFv}$ form (single chain Fragment variable) [1]. By ELISA, we found that this ScFv D anti-estradiol antibody has the same affinity and cross-reactions as the monoclonal antibody (data not shown).

Figure 1 shows the scFv D's cross-reactions. The scFv D cross-reacts only with estradiol-3-sulfate and has a high affinity for estradiol (nanomolar). The aim of our work is to select, using Phage Display technology, an antibody which has a higher affinity for estradiol and no cross-reactions with estradiol-3-sulfate. Sitedirected mutagenesis of some amino acids of Complementarity Determining Regions (CDRs) was performed.

From molecular models of antibody-estradiol complex, residues presumed to interact with estradiol were selected. These residues have been substituted so as to be bigger, smaller or have a different charge from original residue [6]. Results of mutations are shown in Table 1:

- First, some mutants such as GlnH35Lys or AspH96Glu have lost the capacity to recognize estradiol. This residues are certainly involved, either directly or not, in the recognition of estradiol.

- Positions H95 and H97 behave similarly. When the wild-type H95 residue is substituted by a smaller residue (ValH95Ala), the cross-reaction with estradiol-3-sulfate increases. On the other hand, when the two $\mathrm{H} 95$ and $\mathrm{H} 97$ residues are substitued by a bigger residue (ValH95Leu, GlyH97Ala), the cross-reaction decreases. Alanine and Valine may prevent estradiol-3-sulfate presenting the antibody paratope. CDR H3 mu- 


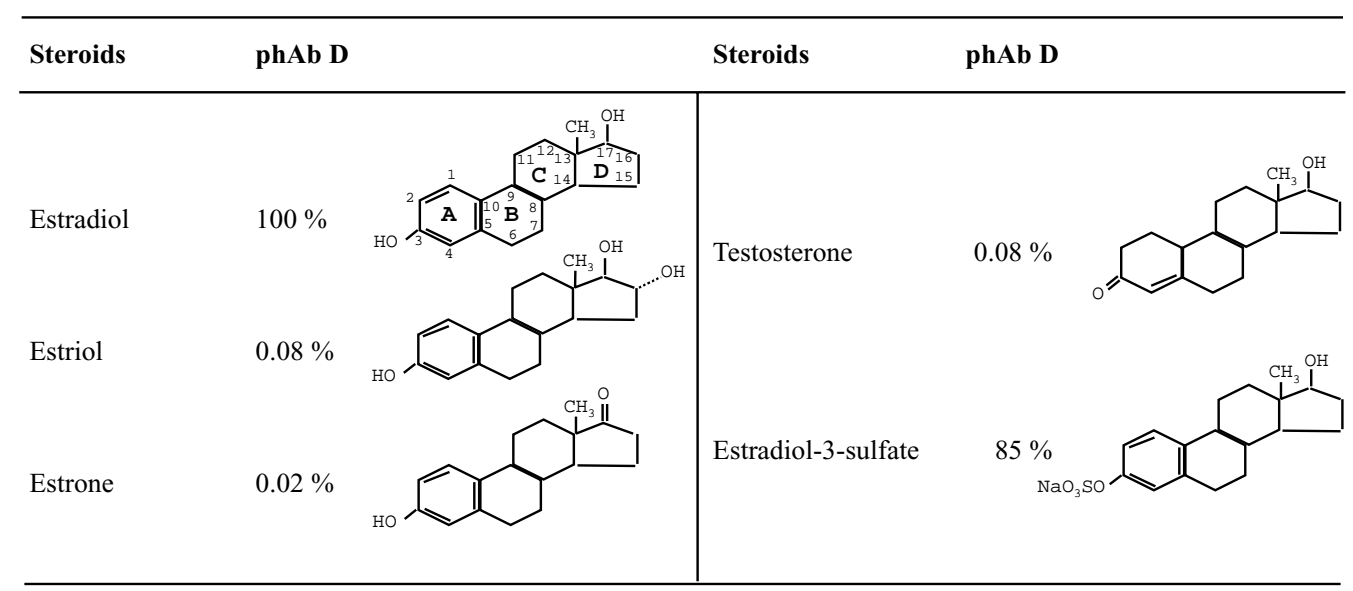

Fig. 1. Cross-reactions of phage antibody D (phAb D) with estradiol analogs. $s c F v$ gene is fused to $g p 3$ gene which code for M13 bacteriophage capsid protein. When cells containing fused gene are infected by M13 bacteriophage, they secrete phage particles where scFv is displayed on phage surface. Phage particles are used to determine percentage cross-reactions of scFv.

Table 1

scFv D site-directed mutants - affinity and cross-reaction with estradiol-3-sulfate obtained by radio immunoassay

\begin{tabular}{lccc}
\hline Mutant & Affinity (nM-1) & \% Estradiol-3-sulfate & CDR \\
\hline WT D scFv & 1 & 85 & H3 \\
ValH95Ala & 6 & 180 & H3 \\
ValH95Leu & 5.3 & 57 & H3 \\
AspH96Glu & 0 & 0 & H3 \\
GlyH97Ala & 0.6 & 42 & H3 \\
GlyH97Val & 0 & 0 & H3 \\
TyrL91Phe & 0.9 & 70 & L3 \\
SerL92Asp & 0.2 & 65 & L3 \\
IleL94Met & 0.2 & 60 & L3 \\
TrpL96Arg & 100 & 48 & L3 \\
GlnH35Lys & 0 & 0 & H2 \\
GlyH97Ala/ & & & \\
SerL92Asp & 0.2 & 45 & H3/L3 \\
GlyH97Ala/ & & & \\
IleL94Met & 0.2 & 48 & H3/L3 \\
\hline
\end{tabular}

tations seems to be important for modifying the specificity of scFv D for the 3-position of estradiol.

- Conversely, mutants modified on L3 CDR (SerL92 Asp, IleL94Met) showed a greater affinity for estradiol than the scFv D.

- For the double mutants (GlyH97Ala/SerL92Asp, GlyH97Ala/IleL94Met), an additional effect was detected: the cross-reaction with estradiol-3sulfate decreases while the affinity for estradiol increases.

From these site-directed mutagenesis experiments we have identified some key residues at positions H96, H97, L91, L92 and L94, involved in estradiol-antibody interactions but we could not deduce the orientation of estradiol in ScFv D paratope from these observations.
In order to improve the specificity of the $\mathrm{scFv}$ $\mathrm{D}$ we have constructed a scFv library from the two site-directed mutants (GlyH97Ala/SerL92Asp, GlyH97Ala/IleL94Met), using DNA shuffling and error prone PCR [7]. This technique is useful to generate diversity and to mix mutations. The VH and VL genes are shuffled, the linker remaining unshuffled [4]. Unfortunately, numerous mutations introduced a "stop" codon TAG in the library. In the suppresive strain ( $\sup \mathrm{E}$ ), employed for phage production, a glutamine residue is often incorporated at the TAG codons. So, $\mathrm{scFv}$ production levels in cells containing TAG codons is decreased. In phage display selection, during amplification steps, some cells grow more quickly than the others. Numerous unspecific phage-scFv which have TAG codon are produced and selected. DNA shuffling library did not allow us to select a mutant devoid of cross-reaction with estradiol-3-sulfate. We are currently constructing smaller libraries shuffled on CDRs $(\mathrm{H} 2, \mathrm{H} 3$ and L3) in the view to generate a recombinant $\mathrm{scFv}$ exhibiting improved binding properties for use in highly sensitive estradiol direct immunoassays.

\section{References}

[1] P. Chames, S. Coulon and D. Baty, Improving the affinity and the fine specificity of an anti-cortisol antibody by parsimonious mutagenesis and phage display, J.I. 161 (1998), 5421-5429.

[2] N.J. Cook and G.F. Read, Oestradiol measurement in women on oral hormone replacement therapy: the validity of commercial test kits, Br. J. Biomed. Sci. 52 (1995), 97-101.

[3] E. Milgrom, Steroid hormones, in: Hormones: from molecules to disease, E.E. Baulieu and P.A. Kelly, eds, Herman, Paris, 1990, pp. 385-437. 
[4] K. Proba, A. Wörn, A. Honegger and A. Plücthun, Antibody $\mathrm{scFv}$ fragments without disulfide bonds made by molecular evolution.

[5] S.C. Samuel, Yen. Clinical Endocrinology of Reproduction, in: Hormones: from molecules to disease, E.E. Baulieu and P.A. Kelly, eds, Herman, Paris, 1990, pp. 445-480.

[6] R. Schier, A. McCall, G.P. Adams, K.W. Marshall, H. Meritt, M. Yim, R.S. Crawford, L.M. Weiner, C. Marks and J.D. Marks, Isolation of picomolar affinity anti-c-erbB-2 singlechain Fv by molecular evolution of the complementarity de- termining regions in the center of the antibody binding site, $J$. Mol. Biol. 263 (1996), 661-567.

[7] W.P.C. Stemmer, DNA shuffling by random fragmentation and reassembly: In vitro recombination for molecular evolution, Proc. Natl. Acad. Sci. 91 (1994), 10747-10751.

[8] D.Y. Yoon, M.J. Choi, I.S. Choe, T.W. Chung and S.M. Byun, Influence of the conjugation site on the specificity of monoclonal antibodies to progesterone and on the performance of direct enzyme immunoassay, Biochem. Mol. Biol. Int. 31 (1993), 553-563. 


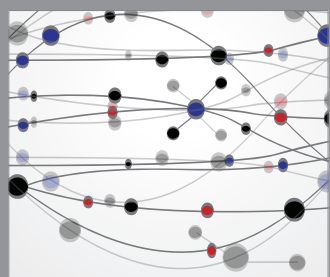

The Scientific World Journal
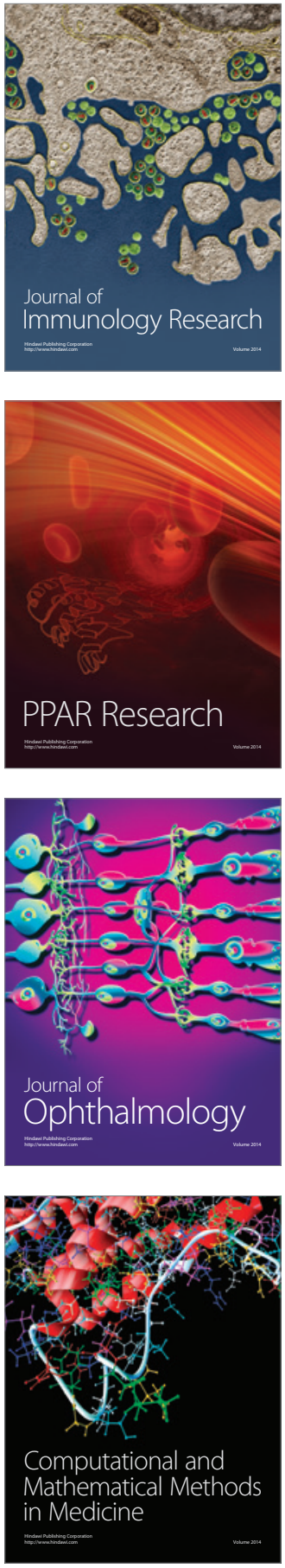

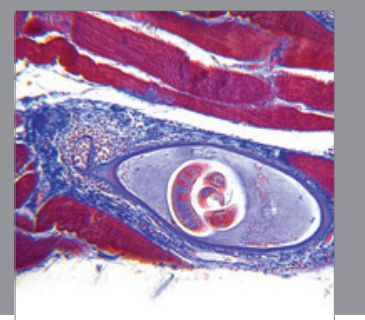

Gastroenterology

Research and Practice
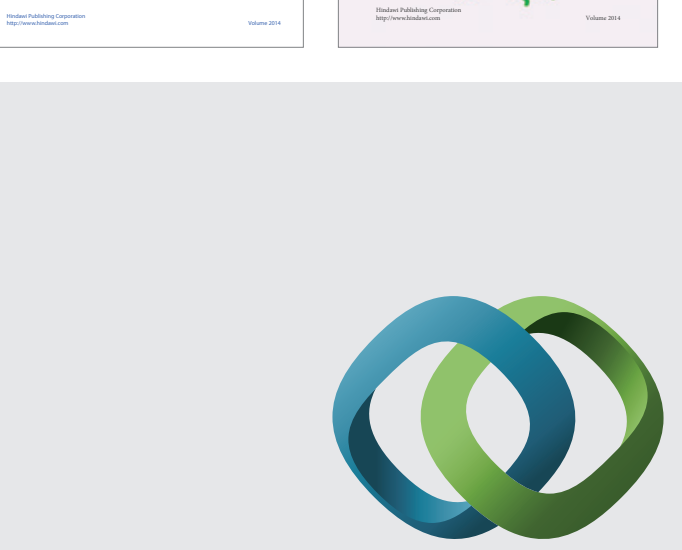

\section{Hindawi}

Submit your manuscripts at

http://www.hindawi.com
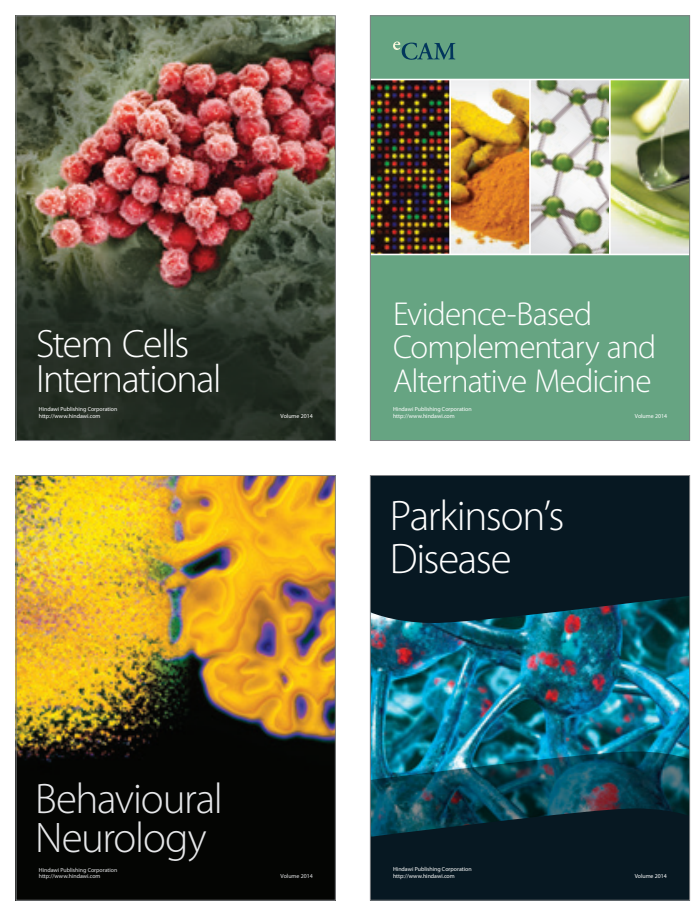

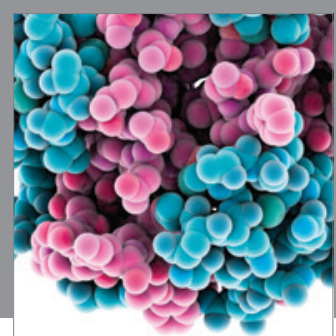

Journal of
Diabetes Research

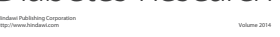

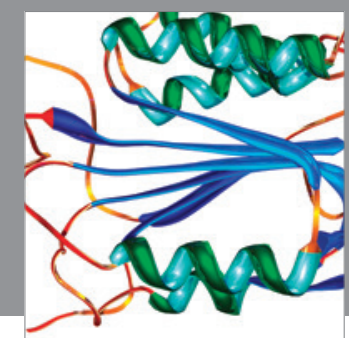

Disease Markers
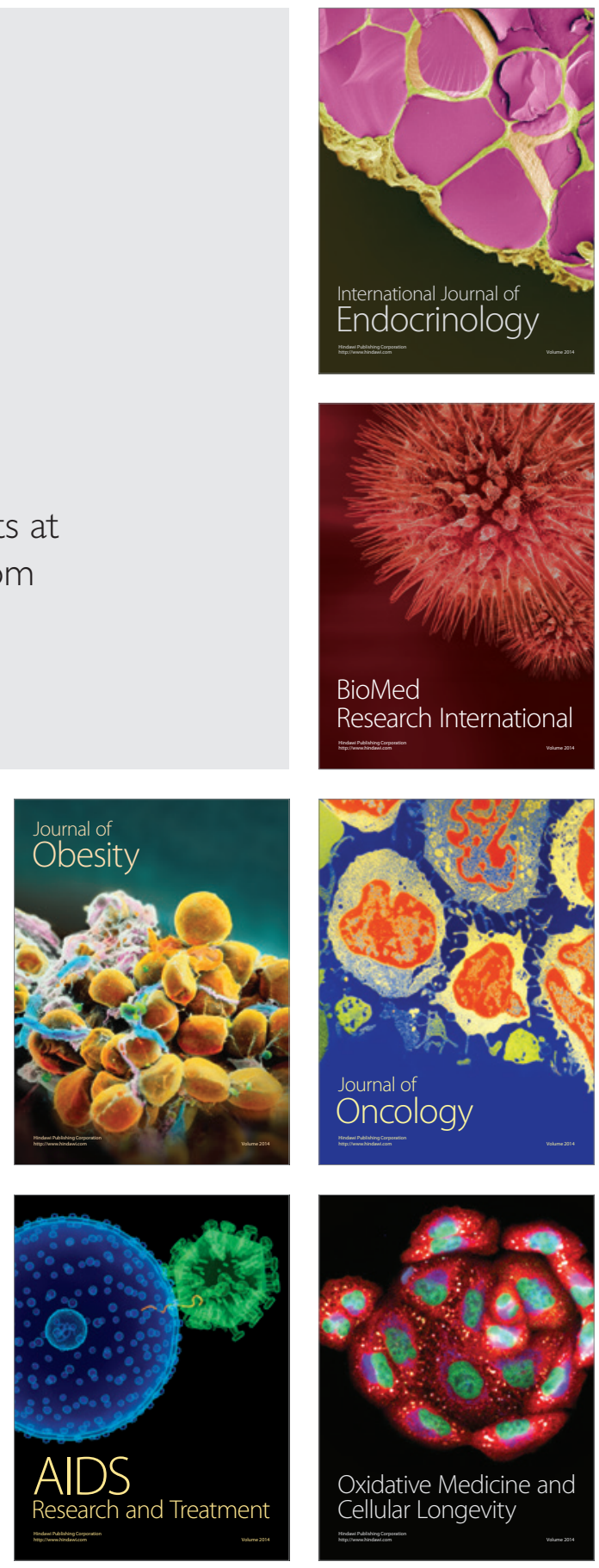